\title{
An Examination of the Qatari Licensure System: Giving Voice to Educators at Government-Funded Schools
}

\author{
Abdullah Abu-Tineh ${ }^{1}$, Hissa Sadiq ${ }^{1}$, Fatma Al-Mutawah ${ }^{1}$, Youmen Chaaban ${ }^{1}$ \\ ${ }^{1}$ College of Education, Qatar University, Doha, Qatar \\ Correspondence: Abdullah Abu-Tineh, College of Education, Qatar University, Doha, Qatar, PO. Box 2713, Qatar.
}

Received: September 17, 2017

Accepted: November 27, 2017

Online Published: November 29, 2017

doi:10.11114/jets.v5i12.2823

URL: https://doi.org/10.11114/jets.v5i12.2823

\begin{abstract}
The issue of developing a comprehensive licensure system aligned with professional standards for teachers and school leaders has received considerable attention in recent years. As part of the Qatari educational reform in recent years, teachers and school leaders are held accountable to offer quality education for all students. The current study thus examined the experiences of educators in Qatar with the licensure process currently implemented at government-funded school. Using a survey study design, a total of 1,669 participants expressed their perceptions on the strengths and weaknesses of the licensure system, the professional standards, and the professional portfolio. Findings included participants' beliefs on the importance of the licensure system in improving their performance, the necessity of using the professional standards as tools for professional growth and development, and the importance of refining the professional portfolio for authenticity and reliability. Documenting teachers' and school leaders' voices was fundamental in finding ways to successfully drive future developments of the licensure system. The findings may also provide implications for other countries interested in developing or refining their own appraisal systems.
\end{abstract}

Keywords: licensure system, professional standards, educator evaluation, accountability, Qatar

\section{Introduction}

Since the mid 1980s, educational systems worldwide have witnessed a proliferation of educational reform initiatives aimed at improving teaching and learning, ranging from new standards and tests, new curricula, and redesigned schools (Darling-Hammond, 2010). Policymakers, practitioners and the general public unanimously agree that the key to reforming, or otherwise improving, education is placing highly skilled and effective teachers in every classroom (Goldhaber \& Anthony, 2007) supported by highly skilled and effective school leaders (Tuytens \& Devos, 2014). As educational standards become ever more sophisticated, educators need to have a repertoire of abilities and skills to reach a more diverse student population and cater to their various needs. Accordingly, ensuring educator quality is one of the most promising strategies for achieving the goals of educational reform (Ingvarson \& Rowe, 2008).

As part of any educational reform, the development of a comprehensive licensure system aligned with professional standards for educators provides a policy mechanism for making features of quality education explicit (Mayer, Mitchell, Macdonald, \& Bell, 2005). Ingvarson and Rowe (2008) articulate, "standards provide the necessary context of shared meanings and values for fair, reliable and useful judgments to be made" (p. 16). They further contend that valid standards and measures of quality education need to be operating effectively at the national or profession-wide level: beginning with the assessment and accreditation of education courses, then at the point of registration of newly employed educators, and finally the certification of accomplished and highly accomplished professionals. Darling-Hammond (2012) supports this process of evaluating educators, but stresses the importance of continuous improvement and support based on such evaluations as part of an integrated system that enables effectiveness throughout an educator's career.

Typically, professional standards articulate what is valued in terms of educational practices and describe the essential features of what educators should know, believe, and be able to do (Isore, 2009). Beyond initial requirements for preparation and qualifications, three areas of teacher quality are commonly associated with standards for licensure requirements, namely, content knowledge, teaching practices and pedagogical procedures, and collaboration with colleagues and the community. For school leaders, standards are associated with leadership, development and management skills. With such standards, policy makers and education authorities aspire to make the teaching profession 
"less variable, more reliable, and increasingly effective" (Mulcahy, 2011, p. 94). However, studies show that "local conditions mediate external policy in rational ways" (Pogodzinski, Umpstead \& Witt, 2015, p. 557). In other words, educational reform requirements will not always be implemented exactly the way policymakers intended.

With this in mind, professional standards should be expressed in performance terms as they "are no longer taken to be a tool for teachers (and others) to use; they are rather an activity in which people might participate" (Mulcahy, 2011, p. 98). Defining standards in this way highlights the variations that intrinsically occur among different practitioners working across different contexts. Accordingly, the development of professional standards embedded within a larger licensure system cannot be simply interpreted as "the knowledge base of the profession" and should be critically examined as they are performed in "localizable practices" (Mulcahy, 2011, p. 95).

In this respect, the Qatari experience with the licensure system for teachers and school leaders should be examined through the perspective of educators who are directly engaged in the implementation of professional standards associated with their evaluation and consequently licensing. In Qatar, recent policies to enhance educator quality have stressed the importance of licensure and certification requirements with the intended purpose that by meeting these requirements, educators are considered to possess the necessary knowledge and skills related to the academic standards expected of students. However, implementation has been challenged by local realities (Ben Jaafar, 2012). As part of an ongoing examination of the reform initiative at the local level, the current study attempts to shed light upon the licensure process, its advantages and disadvantages, as perceived by educators in Qatari government schools.

\section{Review of the Related Literature}

\subsection{Licensure around the World}

Some of the most high-achieving nations have developed national systems of support and incentives to ensure that all educators are well prepared and ready to teach all students effectively. These nations have well-established criteria organizing decisions about entry and continuation in the profession. However, they differ extensively in the ways they approach educator appraisal, ranging from highly sophisticated national systems to informal approaches decided by individual schools (OECD, 2013). Several lessons may be learned from examining both effective and ineffective licensure and appraisal systems.

In several countries, including the UK, Australia, and New Zealand, professional standards have been redesigned to indicate an increased formative approach in such a way that the adopted appraisal system is closely linked to the individual professional development needs of educators working towards different school goals. As part of a monitoring and support program, ongoing performance management cycles constitute the necessary evidence for meeting the standards. In addition, certified assessors/inspectors as well as school-based head teachers/principals consider the extent to which the standards are met before certification is granted to the applicant at different career stages. Teacher standards are complimented by professional standards for school leaders, which provide consistent benchmarks determining what principals are expected to know, understand and do.

While many other educational systems are governed by professional standards, the Finnish experience has provided compelling evidence for an alternative and viable system. In Finland, ensuring quality education begins directly after high school graduation. Becoming an educator in Finland is a very competitive process, and only the best are selected for the profession. Once accepted, these highly capable candidates complete a rigorous university program at the expense of the government. A master's degree constitutes an educators' license into the profession. The school leader further takes on the role of pedagogical leader and becomes responsible for the implementation of measures needed to enhance teacher quality. Consequently, Finnish schools have a system that engages school leaders and teachers in evaluating a teachers' fulfillment of individual objectives set during the previous year and discussing further objectives for the following year. In short, a typical feature of the educational system is the high confidence levels in both teachers and principals as professionals.

Singapore, another top-performing nation, emphasizes student learning and development, teacher collaboration, professional development and working with parents in its evaluation system. Similar to Finland, Singapore has refined its incentive structure, which begins directly after high school graduation. Top-performing students consistently apply and compete to become teachers. With the right mix of training, support and accountability, all educators are expected to possess quality education traits necessary for successful student learning. Throughout their careers, the model for educators' evaluation is based on competencies (rather than standards) that constitute rating scales of increasingly more effective levels of behavior within each competency. The strength of the model lies in its ability to link an educator's performance on this competency scale to the successful attainment of educational goals, which educators set for themselves at the beginning of each academic year. Ongoing assessment and discussion meetings with supervisors, accompanied with constructive criticism and advice for professional development opportunities, ensure that educators progress towards their competency goals. 
Unlike these well-performing nations, researchers in the US contend that their current evaluation systems have failed to separate teachers who are effective from those who are not (Pogodzinski, Umpstead \& Witt, 2015), even though a heavy emphasis on both teacher and student testing requirements are emphasized. While each state sets its own procedures for licensure, teachers in almost all states are required to pass at least three tests, including multiple-choice tests of basic skills, subject matter, and teaching knowledge, in order to become licensed. Further, in most states, school leaders evaluate teacher performance once a year using a binary sheet on which they check off whether the teachers' performance is either satisfactory or unsatisfactory on a list of items. In recent years, another measure of accountability adopted by several states includes measuring teachers' contributions to student achievement gains on high-stakes examinations. This process incorporates value-added methods for examining students' learning gains into teacher evaluation, while controlling for external influences at the student, classroom, and school level.

Despite the fact that educator evaluations take place on a regular basis in many countries, it should be noted that no Arab country, excluding Qatar, has a coherent and well-resourced appraisal system in place (Ben Jaafar, 2012). For this reason, the current study may provide further implications for neighboring Arab countries interested in developing their own appraisal systems within similar contexts to the Qatari educational system.

\subsection{Licensure in Qatar}

The Qatari educational system underwent an extensive reform in 2004, known as Education for a New Era, under the auspices of the RAND Corporation, a nonprofit research organization. After examining Qatar's K-12 education system, the organization provided recommendations and options for building a world-class system in an attempt to eradicate concerns about the low outcomes of Qatari students on international tests (Zellman et al., 2009). The reform was based on the notion that "no matter what else was to occur, the basic educational elements of a standards-based system had to be put in place" (Brewer, et al. 2007: xviii).

International consulting organizations were hired to offer their expertise in a variety of areas, including the development of a system for the registration and licensing of teachers and school leaders. The resulting document prescribed 12 professional standards for teachers and 7 professional standards for school leaders developed by Education Queensland International (EQI) of Australia in 2007. The development of professional standards for teachers and school leaders in Qatar has been a policy response for improving the quality of the educational system and enhancing the status of the teaching profession. The licensure system was aligned with these national professional standards and provided the Supreme Education Council (SEC) [the government agency that oversees all educational matters in Qatar] measurable benchmarks for managing, monitoring, and evaluating the practice of educators in Qatari government schools. According to the SEC, the standards were "developed taking into account the real education environment in Qatar and the goals of the reform initiative" (Supreme Education Council, 2007).

As a further development, the SEC's Professional Licensing Office (PLO) became responsible for overseeing the quality of teachers' and school leaders' practices and making sure they were aligned with the national professional standards. The PLO awards professional licenses for teachers at three levels (entry, proficient, and advanced) and for school leaders at two levels (middle management and senior management). Specifically, the standards consist of a set of statements describing desired knowledge and abilities at various points in an educators' career, in addition to indicators for measuring appropriate levels of achievement of each standard and an evidence guide for specifying the performance expected at each level of career development. To ensure the successful progression through the licensure system, the SEC plays an integral role in supporting teachers and school leaders by offering professional development opportunities based on the professional standards (Supreme Education Council, 2007).

To obtain a full license, teachers follow procedures that are quite similar to those followed by school leaders. At the entry level, teachers are granted a provisional license once they have been registered electronically at the PLO and their degrees and experience have been verified. To attain a complete license, candidates must complete an electronic portfolio that includes evidence for the implementation of each professional standard along with a written narrative explaining how the selected evidence meets the standard. Once completed, the portfolio is submitted to the schools' Attestation Committee, which is composed of 7-11 individuals: the school Principal, Vice Principal, four curriculum coordinators, and up to two teachers representing both art and science streams. A final approval is issued by the PLO and the candidate is granted a full license. Teachers are required to submit their portfolios within three years from the time of registration in order to obtain the proficient license. The same process is repeated within three years of obtaining the proficient license in order to acquire the advanced license. School leaders also prepare an electronic portfolio that includes pieces of evidence for the implementation of each professional standard. However, they submit their portfolios to an external committee affiliated with both the SEC and Qatar University (College of Education). Not only must school leaders understand, practice and appreciate their own professional duties as dictated by their professional standards, they must also respond to the needs of their teachers, so they too meet their own professional standards. 


\subsection{Professional Standards: Development or Regulation?}

There has been considerable debate not only about the ways in which standards might be used to ensure quality in education, but also about whether they can achieve such an end (Mayers, et al. 2005). Researchers tend to disagree on the benefits of standards, as some see them as useful ways of clarifying processes and expectations while others consider them a means of tightening regulations (Forde, McMahon, Hamilton, \& Murray, 2016).

A critical examination of professional standards suggests that they may be used as a way of controlling educators (Ingersoll, 2011). They have the power to demand what and how educators perform their professional duties and then hold them accountable for decisions in which they do not have any say. Researchers have contended that rather than questioning the value of standards, what is questioned is the way they may be imposed upon the profession as controlling devices (Sachs, 2003). Policy makers reserve the right to make all decisions without involving educators, except when it comes to accountability. When this happens, educators may be denied the control and flexibility they need to accomplish their work effectively (Sahlberg, 2011).

As part of controlling educators' actions, Sachs (2003) argues that standards may further become ideological tools for educators "to do more under the guise of increasing their professionalism and status" (p. 184). Such work overload is likely to influence educators' performance, engagement and receptiveness to change (Sachs, 2003). Tuinamuana (2011) further argues that with the intensification of educators' workloads and accountability, no more than token efforts are exerted in implementing standards, which may result in sabotaging centralized efforts at reform. Webb (2006) goes even further to note observations of educators" "fabricated" performances in order to satisfy accountability demands.

Another source of criticism lies in the assumed link between the standards reform and student learning outcomes. The link between teachers who have been through the certification process and enhanced student gains has not been empirically validated with sufficient research (Sharkey \& Goldhaber, 2008). In fact, using students' test scores on high-stakes examinations is a controversial issue in itself (Polikoff \& Porter, 2014). Proponents of this method of teacher evaluation contend that such accountability measures are an objective and fair measurement of the contribution made by an individual teacher towards students' achievement. Thus, they have the potential to exclude certain individuals who would make for ineffective teachers (Isore, 2009).

Opponents have expressed concern about their volatility at the individual teacher level, the possibility they could encourage teaching towards tests, the fact that score gains measure more than the influence of the teacher, and the possibility of bias if some teachers are given students who are more difficult to teach (Darling-Hammond, 2010).

Some researchers claim that establishing professional standards and rigorous licensing systems may lead, in the long run, to increased attrition rates (Ingersoll, 2011). Such a consequence is considered in light of the decline in the attractiveness of the teaching profession, which lacks occupational prestige, generous salaries, and opportunities for growth and advancement. In addition to several other non-attractive factors, such as heavy workloads and student disciplinary problems, imposing higher standards for entering the profession may discourage many qualified candidates interested in pursuing a career in education (Angrist \& Guryan, 2008).

There is also a concern raised when standards are imported from Western educational systems. When this happens, standards become a body of objective knowledge beyond criticism (Romanowski \& Amatullah, 2014). The fact that various countries have adopted the same language to describe their reforms does not ensure the successful transferability from one context to another. Standards-based reform that is neither locally developed nor context sensitive has been criticized as leading to resistance among educators, a lack of ownership, and little opportunity for critically evaluating its effectiveness (Ellili-Cherif et al., 2012). Reform ideas introduced from outside the system further limit the role of national policy development and the enhancement of an educational system in its ability to maintain renewal (Sahlberg, 2011).

In contrast to this negative view of professional standards, some consider them an important factor in improving educational systems and the practices of educators in schools (Tuinamuana, 2011). As commonly defined, professional standards make explicit the knowledge and capabilities of educators, and provide a means by which quality educators can be recognized, rewarded, and celebrated (Mayer et al., 2005). In this way, standards can lift the status of educators in the public perception (Tuinamuana, 2011) and consequently contribute to the professionalism of the profession and the social recognition of educators' skills and commitment to work (Isore, 2009).

Another argument in favor of standards is that setting equal standards for all ensures equity in the distribution of highly accomplished teachers across schools (Ingvarson \& Rowe, 2008). Since the ultimate goal of schooling is the enhancement of student learning opportunities, setting standards ensures that all students are offered equal opportunities to quality education regardless of their origin, gender, socioeconomic status and so forth. Based upon such standards, policymakers would have a means of holding educators accountable for quality education (Isore, 2009). 
Equally important to the regulation of educators' work is the use of standards as part of a system of professional learning and growth (Mayer et al., 2005). In this way, standards can provide a framework for professional learning that can be used by educators in planning their professional development activities as they advance throughout their careers (Forde et al., 2016). Ingvarson (1998) argues that standards can become the basis of a "professional development system", through which educators are encouraged "to create a strong sense of ownership for its quality" and "continually review their practices in light of contemporary research and professional standards" (p. 131). Darling-Hammond (1999) also highlights the way in which standards "hold promise for mobilizing reforms...and helping to structure the learning opportunities" of educators in a complex system (p. 39).

As such, standards may serve contradictory purposes, both developmental and regulatory, depending on the way they are regarded: "either standards as documents that prescribe sets of practices or as documents that set out the broad parameters which are then contextualized by the teacher or leader in their own professional context." (Forde et al., 2016, p. 24). Thus, intrinsically speaking, standards are not necessarily tools that support or enhance the quality of education. Rather the ways they are defined and used determines their true value (Mayer et al., 2005). In this paper, we are concerned with the ways educators at Qatari government schools perceive the true value of the licensure system in general and the professional standards for teachers and school leaders in particular.

\subsection{Rising Concerns}

Several problems with current measures of educators' evaluation have been documented internationally and more specifically within the Qatari context. Locally, Ellili-Cherif, Romanaowski, and Nasser (2012) investigated the perceptions of 74 school leaders regarding the licensure system and the professional standards for school leaders. Results indicated that the policies (1) use ambiguous terminology and procedures as one piece of evidence could be used to support several standards, which could further be interpreted in various ways, (2) ignore local educators' input and culture, (3) provide unrealistic expectations of teaching practices with an overreliance on paper evidence in the submission of the portfolio, (4) lack consistency and reliability, including the influence of personal relationships between teachers and the schools' Attestation Committee on licensure decisions, and (5) create resistance on the part of educators as radical changes were required on many different levels. The researchers make the claim that the educational system has undergone countless reforms by "letting market oriented policy makers determine the choices for the general public with profit at the center and surpassing the common good" (p. 473). They argue against the notion of importing western forms of knowledge, which are typically considered superior forms of knowledge readily accepted by Qatari policy makers, though not necessarily by educators.

In another national study, Romanowski and Amatullah (2014) raised further concerns in examining 333 teachers' perceptions towards the implementation of the professional standards as a requirement for licensure. The researchers concluded that the participants in their study (1) were more concerned with personal issues such as workload, rather than providing sound educational arguments about the value of standards, (2) viewed the professional standards only as a means to obtain licensure, and (3) were obsessed with the standards in ways that distracted them from more important aspects of teaching and professional development. The researchers stressed the importance of teachers' understanding of the discourse of standards and how such discourse shapes their pedagogy.

Internationally, the belief that the licensure process and professional standards will improve educators' practices and consequently students' learning outcomes has been brought under strict scrutiny (Goldhaber \& Anthony, 2007). Louden and Wildy (1999) summarize three common objections against standards frameworks that have relevance to the context of the current study: First, they question the relationship between professional standards and practice, specifically as they are implemented across a range of diverse settings. For any particular standard, the context in which it is applied will vary, as will the performance required of the educator. Therefore, any performance that seems to correspond to a certain standard may require a range of different knowledge and skills in different contexts. Such considerations may be examined through the voices of educators who have implemented the standards at various Qatari government schools.

Second, professional standards frameworks have been criticized as dividing complex professional practice into hierarchical lists of dispositions, knowledge or duties. This fact duly applies to the Qatari professional standards document that includes numerous lists of standards. Accompanying each standard are various statements, numerous indicators and descriptions for required skills, knowledge and dispositions, as well as evidence guides on three levels for teachers and two levels for schools leaders. Large variations in interpreting the content of the standards may exist among educators, which may lead to differences in their implementation. A third criticism made against standards is that the wording of items implies a degree of precision that is difficult to achieve in real contexts. Such wordings allude to "false dichotomies", in such a way that a clear judgment of competency is difficult to achieve. In light of such criticisms, the current study examines the experience of educators in Qatar with the standards document and their perceptions regarding its clarity, viability, reliability and validity. 


\section{Methodology}

\subsection{Giving Voice to Educators at Qatari Schools: The Current Study}

The scarcity of empirical research on the licensure system in the Qatari context is surprising, given the fact that it has been criticized for being adopted from western ideologies, rather than being adapted to fit the Qatari cultural context (Ellili-Cherif et al., 2012). The implementation of the current licensure system and the adoption of the professional standards have remained unchanged and unquestioned since 2007. Little is known about how teachers and school leaders perceive the licensure system, how they interpret and use the professional standards, and how they prepare their portfolios for evaluation. Teachers' and school leaders' voices need to be heard if future developments of the licensure system are to be successful. By educators' voice, we do not simply mean their discussion of issues related to pedagogy, curriculum, classroom management, or other educational topics. It also does not mean their discussion of compensation, benefits, work responsibilities, or other employment issues. Our concern is educators' policy voice which covers a range of topics that are decided outside of the school, such as the licensure system (Gyurko, 2012). Teachers' and school leaders' input on the strengths and weaknesses of the current licensure system, as well as their recommendations for improvement can provide useful information for policy makers attempting to create a more reliable licensure system and for professional development providers seeking to offer more powerful learning opportunities for educators based on the standards.

The Professional Licensure System Instrument (PLSI) was specifically developed to measure participants' perceptions of the professional licensure system which was launched in 2007 in Qatar. The questionnaire provided the first quantitatively descriptive look at the process that moves teachers and school leaders from their point of entry into the profession through their certification as accomplished professionals. Equally important was participants' qualitative perspective regarding the strengths and weaknesses of the licensure system. The PLSI was reviewed by 12 professors and professional development specialists in the educational field and 4 of them asked for modifications. The final survey consisted of 32 items on a five-point Likert scale ( $1=$ strongly disagree; $5=$ strongly agree) and 4 open-ended questions. The 32 closed-ended questions rated participants' perceptions regarding the professional licensure system in terms of three dimensions: (a) professional licensure system; (b) professional standards; and (c) professional portfolio. The 4 open-ended questions addressed the strengths and weaknesses of the licensure system, professional standards, and professional portfolio.

In order to ensure the psychometric properties of the instrument, internal consistency measures of reliability were computed for the three sections of the instrument by calculating Cronbach's alpha coefficients of each section. Alpha scores for all sections were between 0.78 and 0.86 . With these internal consistency ratings, the PLSI instrument was regarded to be an appropriate instrument for the present study.

The data collection method was the self-administered paper-based PLSI questionnaire. Questionnaires were distributed to participants at their workplaces for completion at their own convenience to ensure anonymity. Participants consisted of a total of 1,669 Qatari government-funded school teachers and school leaders. Specifically, 998 school teachers, 391 subject coordinators, 182 vice principals, and 98 principals agreed to participate in the study by voluntarily completing and returning usable surveys. The analysis of the data consisted of descriptive statistics, including computing the mean for each statement and comparing the results. More importantly, participants' responses to the open-ended questions were analyzed using the constant comparative method (Miles and Huberman, 1994). This method included an iterative process of reading and rereading the written responses, isolating important responses into a spreadsheet, searching for patterns in the data, categorizing the data, and finally comparing the categories to the quantitative data. This allowed for an in-depth understanding of their perceptions towards various aspects of the licensure system.

\section{Findings and Discussion}

\subsection{The Licensure System Improving Educator Performance}

According to the results of the study, the most controversial aspect of the licensure system concerned its relation to educator performance. Educators have commonly been accused of rejecting any licensure system as it places unattainable expectations on their performance. This argument has been used against educators who call for amending or cancelling the licensure system altogether. Contrary to this common misconception, quantitative self-reports of educators who participated in this study revealed that educators in Qatar perceived, to a moderately high level, the positive impact of the licensure system on their teaching and leadership practices. To their credit, participant educators believed that the licensure system promotes education as a profession, ensures qualified educators to teach and lead, and encourages educators to continue and sustain their professional learning (see Appendix 1). Therefore, the licensure system was not in itself considered the source of frustration among educators in Qatar, but the complicated procedures, the overreliance on paper evidence, and the use of ambiguous terminology. Participant educators perceived the licensure system procedures to be unclear, long and complicated. Further, the number of supporting employees was perceived to be limited, and booklets, brochures, and manual were not adequately available. 
Table 1. Professional licensure system as perceived by educators

\begin{tabular}{lcc}
\hline Statement & Mean & SD \\
\hline The professional licensure system is an additional burden on teachers and school leaders. & 3.83 & 1.10 \\
Procedures of the professional licensure system are long and complicated & 3.78 & 1.04 \\
The professional licensure system improves the performance of teachers and school leaders. & 3.73 & 1.16 \\
The professional licensure system promotes teaching as a profession & 3.72 & 1.18 \\
The professional licensure system ensures the enrollment of qualified educators in the schools. & 3.69 & 1.17 \\
The professional licensure system encourages educators to continue and sustain their professional learning & 3.66 & 1.11 \\
The professional licensure system encourages active participation in educational decision-making & 3.29 & 1.19 \\
The staff at the Professional License Office has sufficient experience & 2.82 & 1.00 \\
The requirements and procedures of the professional licensure system are clear & 2.80 & 1.15 \\
The professional licensure office has enough staff to follow up on professional licensure affairs in schools & 2.65 & 1.03 \\
Brochures, booklets, and manuals of the professional licensure system are adequately available & 2.64 & 1.17 \\
\hline
\end{tabular}

Responses on the open-ended questions of the survey revealed consistent results. Many participants agreed that the licensure process was a necessary undertaking for monitoring the quality in schools, acknowledging educators' accomplishments, and obtaining the license to teach. One participant explained:

The licensure process is a burden on teachers, but without this step, the Ministry cannot monitor the quality in the schools. The standards provide a clear picture of an effective teacher; someone who can enhance student learning.

Several other participants who considered the licensure process a burden on educators believed that it was the only way "teachers' accomplishments would be revealed," an effective way for "providing structure for educators' roles and responsibilities," and most importantly, the "only way they can teach is after obtaining a full license."

So what has caused educators to become frustrated with the licensure system? Or more specifically, why were educators against the current licensure system? Generally, most participants expressed their discontent towards the current licensure system, describing it as stressful, depressing, challenging, and time consuming. Additionally, taking time to complete their portfolios was difficult for many participants, especially those who did not believe there was enough support provided. One participant explained:

Completing the portfolio is time consuming and it doesn't have any benefits. Teachers should not have to prove they are competent by gathering some papers as evidence of their work.

Other negative perspectives were mainly expressed by participants who had a difficult time accessing the electronic system to input required information for the portfolio, as well as from participants who did not receive help or support from administrators or the members of the school committee. Consequently, "it is better for a teacher to use her time and effort on teaching her students and helping them achieve educational standards."

\subsection{Using and Refining Professional Standards for Educator Development}

Quantitative data yielded important findings regarding educators' perceptions about the professional standards. Educators in Qatar perceived that the professional standards have moderate to high importance. They believed that these standards have the potential to promote their performance, form a comprehensive map for their teaching and leadership practice, identify required knowledge, skills, and dispositions, as well as direct their professional learning. However, they also perceived that they could do their job without professional standards as education is not a profession that could be restricted by standards.

Table 2. Professional standards as perceived by educators

\begin{tabular}{lcc}
\hline Statement & Mean & SD \\
\hline Professional standards need to be revised & 3.73 & 1.10 \\
Professional standards contain unclear concepts and terms & 3.71 & 1.13 \\
Professional standards contain many unnecessary details & 3.71 & 1.10 \\
Professional standards help me identify the required knowledge, skills and dispositions & 3.69 & 1.04 \\
Professional standards improve my performance & 3.67 & 1.07 \\
Professional standards form a comprehensive map of the teaching and leading practices & 3.61 & 1.05 \\
Professional standards are consistent with the nature of educational system in Qatar. & 3.48 & 1.00 \\
Professional standards include measurable evidences & 3.46 & 0.99 \\
I can perform my work without professional standards & 2.56 & 1.24 \\
\hline
\end{tabular}

The open-ended questions on the survey helped to clarify teachers' perspectives on the professional standards. As well as helping to identify the broader range of knowledge, skills and attitudes, several participants felt the standards helped them to describe their development over time: 
Using the standards as a guide, a teacher can show how much she has developed and prove that she is an effective teacher. They can also be considered an incentive for teachers to improve their practices throughout their careers.

Other teachers considered the standards as a reflection tool; a way to identify their strengths and weaknesses. One participant explained:

The standards have two benefits. First, they indicate how much a teacher has accomplished. And second, they indicate the areas of improvement. The standards help teachers reflect on their teaching and know their strengths and weaknesses.

Several participants further believed that using the standards as a reflection tool had positive outcomes on student achievement. This participants' comment was reflected in several answers:

Teachers are able to improve their instructional practices. The standards remind teachers of effective practices that they may have forgotten. This is reflected on the students' achievement levels.

In fact, there was support for the standards emphasizing professional development from many participants. One participant described the ways the standards can be used as a way to structure the professional needs of teachers in a department. Another described the strengths of the standards in helping teachers identify their own professional needs. One participant explained:

The standards provide the opportunity for continuing professional development. When creating department professional development plans, the standards are useful for indicating the knowledge and skills that teachers need to focus on for that year. The following year, other standards can become the focus.

Despite the generally positive response to the standards on their ability to improve teaching practices, there was, however, a recurring concern that the standards did not allow for a full description of the practices performed by effective teachers. There was an agreement amongst several participants that teaching was a respectful and reverent profession that could not be restricted to a few standards.

The standards can describe tangible skills and knowledge, but there are other attributes that make a teacher successful in teaching. For example, having good relationships with students, caring for their well-being, and dedicating extra time and effort to help them succeed. These attributes are not reflected in the standards.

Further quantitative findings revealed that educators perceived clarity of the professional standards to be low. They believed that the standards contain unnecessary details, include unclear concepts and terms, and need to be rephrased and revised. Further, the professional standards were believed to be inconsistent with the educational system in Qatar and do not include enough measurable evidence.

In discussing their perspectives on the standards, several participants expressed negative perception about the number and wording of the standards. This participant's comment is indicative of many others:

There are too many standards. The twelve standards can be reduced to half and they will still have many details. In their current form, they are redundant and not written clearly because they were translated from English.

A common theme among participants was that the standards required revision and rephrasing. Some participants noted that several standards were repetitive, while others explained that the same evidence could be provided for more than one standard, thus making the process unclear and incredulous.

Elaborating on this point, several participants indicated that they had little documentation that can be used as evidence for some standards. One participant explained:

The documentation of teacher learning is very difficult to achieve. Attending workshops and conferences cannot guarantee that a teacher has learned new knowledge and skills, and whether this learning has any impact on the students' learning.

Further, there was concern for the general nature of the standards. Participants explained that "it is easier for some subjects to provide rich evidence and complete the portfolio quickly. In other subjects, it is more difficult." Some participants indicated that the standards need to be revised to "reflect the specific nature of the different subjects, rather than being general."

\subsection{Redefining the Professional Portfolio for Authenticity and Reliability}

If ever there was a controversial component of the licensure system in Qatar, it was the professional portfolio. The problems associated with preparing the portfolio and the provided support to prepare it were numerous and varied. Educators in Qatar rated the procedures of preparing the portfolio to be the least satisfying. They believed that (a) procedures of preparing the portfolio are unclear; (b) required evidence is difficult to collect; (c) fake evidence is easy 
to provide; and (d) time specified to collect the evidence is insufficient. Further, educators in Qatar believed that the professional portfolio does not reflect the competency of teachers and school leaders.

Table 3. Professional portfolio as perceived by educators

\begin{tabular}{lcc}
\hline Statement & Mean & SD \\
\hline It is easy to provide fake evidences to the professional portfolio & 3.84 & 1.24 \\
The school provides sufficient support to prepare the professional portfolio. & 2.47 & 1.00 \\
Collecting required evidences for the professional portfolio is easy & 2.39 & 1.13 \\
The professional portfolio reflects the competency of teachers and school leaders & 2.28 & 1.25 \\
Qatar University provides sufficient support to prepare the professional portfolio & 2.24 & 1.14 \\
Procedures and steps for preparing a professional portfolio are clear & 2.19 & 1.16 \\
The Evaluation Institute provides sufficient support to prepare the professional portfolio & 2.18 & 1.09 \\
The Education Institute provides sufficient support to prepare the professional portfolio & 2.18 & 1.10 \\
The time specified to collect required evidences is sufficient & 2.15 & 1.00 \\
\hline
\end{tabular}

Several participants addressed the issue of honesty and integrity of writing the portfolio when answering the open-ended questions, stating, "there are many teachers who have low proficiency levels in teaching their classes, yet are able to make up evidence and put it in the portfolio. Where is the honesty in that?" This particular participant, as well as several others, complained that many teachers paid to have their portfolios completed. One participant further explained:

I think the portfolio should be cancelled because it only reflects a number of worksheets and activities that have not been implemented inside the classroom; they are only to fill in the portfolio and obtain licensure. Even when some teachers implement good practices inside the class, they only do so to obtain licensure. Following this, a teacher goes back to her usual way of teaching.

Several participants recommended having an observation component as an additional requirement to validate the practices "claimed" in the portfolio. Several participants, in this regard, believed that the observations have the ability to reflect educators' true competency when they are observed performing their work inside the classroom and when there are established criteria for ensuring the validity of the evidence. "An observation component would differentiate those who are truly great teachers from those who make up evidence and teach ineffectively," and "evaluating teachers using multiple methods can ensure validity" are two recommendations for overcoming the issues of honesty and integrity.

Finally, quantitative data revealed that educators in Qatar perceived the support offered to prepare the portfolio to be moderately low. While they perceived schools, the evaluation institute, the education institute, and Qatar University as institutions which did not provide adequate support, they rated schools as the most beneficial source of support and Qatar University as the least useful.

Qualitative data, similarly, revealed that participants expressed ambivalent perceptions towards the support they received to complete the portfolio. Several participants explained the need for professional development that targeted the procedure for completing a portfolio successfully. In this respect, Qatar University was regarded as the educational institution that could provide this much-needed support. One participant explained:

Teachers need workshops from the same source, so they can all have the same opportunity to understand and prepare the portfolio.

Participants also pointed out the role of administrators in supporting portfolio completion. Rather than using the standards as a regulatory tool, participants wanted their principals to use them as a common language for professional growth. This teacher's response is indicative of other participants:

Many principals are using the standards as a way to assess their teachers. I don't think the intention was for using them in this way. We need principals to use the standards as a way to support us in achieving them, and consequently becoming better teachers.

Participants also expressed their need for leadership support in preparing the portfolio. Principal support could be provided when "they complete their portfolios first. They will have a clearer idea of what is required and they will be able to transfer this experience to their teachers." Especially for certain standards, such as providing evidence for teacher learning, teachers requested clarity and concrete examples that they could provide in their portfolios. One participant explained:

Teachers need workshops that show them the kinds of evidence they can provide for the portfolio. For each standard, teachers can collaborate and brainstorm on the types of evidence they can provide. What happens in some schools is that teachers compete against each other and don't share their experiences. 


\section{Conclusion \& Implications}

\subsection{Creating a System for Reliable Educator Licensure}

The past 20 years have seen a proliferation of empirical research into various licensure systems. Extensive quantitative work investigates these systems of appraisal from different countries, but there is far less research on the implementation of the Qatari licensure system and the adoption of professional standards (Romanowski \& Amatullah, 2014).

Although there are limitations in drawing far-fetched generalizations from this study with its limited interferential statistical analysis, nonetheless, we provided a quantitatively and qualitatively descriptive look at the process that moves educators from their point of entry into the profession through their certification as accomplished professionals. Specifically, we focused on the perceptions of teachers and school leaders on the licensure system currently adopted by the SEC. The paper aims to inform progress towards a system of reliable, valid, and nationally appropriate teacher and school leader evaluation procedures. Such a system can support decision-making based on a common, comprehensive set of standards that ensures the placement of only the most effective educators in Qatari schools.

Findings from this research were extensive and were, indeed, informative. Policy makers at Ministry of Education and Higher Education and other key actors should consider the following recommendations that emerged from the findings of this study and the reviewed literature to avoid several pitfalls in the current licensure system.

Licensure systems should conform to the basic demands of teachers and school leaders as revealed in the findings of this study. Several of these demands include (1) the efficiency and manageability of the system in ways that prevent extensive time and resources spent away from instruction, (2) the encouragement of collegiality and collaboration among educators, rather than isolationism and competitiveness, (3) the inclusion of multiple sources of evidence, such as classroom observations, interviews, portfolios, student learning outcomes, and surveys, (4) the consideration of contextual factors, and (5) the discouragement of gaming procedures that lead to the inappropriate manipulation of results (McMillan, 2016).

Most importantly within such a systematic approach to educator licensure and certification is the alignment of the system to students' academic standards, or what students are expected to know and do. In other words, for educational reform to be effective, licensure systems need to ensure that educators possess the necessary qualifications, knowledge, and pedagogical skills commensurate with students' academic standards (Darling-Hammond, 2014).

Further, educators should be provided with opportunities to engage in critical reflection about the standards and their use in order to negotiate the contradictions and dilemmas of accountability measures in light of their own experiences, beliefs, educational philosophies and classroom practices (Romanowski, 2014a and 2014b). Sachs (2003) supports this notion of discussing and debating the form, content and effects of standards on the profession, and recommends that these standards become internally regulated by educators themselves, rather than externally controlled by governments. In this way, educators should be encouraged to play a more prominent role in implementing the standards as reflective and planning tools within their particular contexts (Forde, et al., 2016). In fact, all key actors, especially schools leaders and teachers, should be involved in the initial conception of any appraisal system. Such participation may ensure stronger commitment and acceptance of the system (Isore, 2009).

Another possible recommendation is a call for a more systematic approach to building educator effectiveness, "beginning with recruitment and preparation and continuing through evaluation and career development" (Darling-Hammond, 2012, p. 9). Thus, the purpose of measuring educator quality should not only be restricted to making decisions on recruitment and retention. Rather, developing the effectiveness of educators should be embedded within a comprehensive system of licensure. Darling-Hammond outlines several elements that should anchor a coherent approach, including common professional standards, performance-based assessments based on these standards, on-the-job evaluations using multiple measures aligned with the same standards, support structures for educators requiring additional assistance, and aligned professional development learning opportunities that support continuous improvement.

Finally, conducting a pilot implementation before full implementation is a cost-effective way to ensure the reliability and viability of the system (Isore, 2009). However, moving on to full implementation after the pilot may further reveal other implementation problems, which may, in turn, lead to educators' objections and/or rejection of the system. Therefore, a critical review of the system, especially one that is associated with educators' perceptions, remains a crucial undertaking.

\section{Acknowledgment}

This article was made possible by NPRP grant \# 7-1224-5-178 from the Qatar National Research Fund (a member of Qatar Foundation). The statements made herein are solely the responsibility of the authors. 


\section{References}

Angrist, J. D., \& Guryan, J. (2008). Does teacher testing raise teacher quality? Evidence from state certification requirements. Economics of Education Review, 27(5), 483-503. https://doi.org/10.1016/j.econedurev.2007.03.002

Ben Jaafar, S. (2012). Leadership in Qatar's Educational Reform. In L. Volante (Ed.), School Leadership in the Context of Standards-Based Reform (pp. 229-246). Springer: Netherlands. https://doi.org/10.1007/978-94-007-4095-2_10

Brewer, D. J., Augustine, C. H., Zellman, G. L., Ryan, G. W., Goldman, C. A., Stasz, C., \& Constant, L. (2007). Education for a New Era: Design and Implementation of K-12 Education Reform in Qatar. RAND Corporation: Santa Monica, CA. Retrieved from: http:// www.rand.org/pubs/monographs/MG548.html

Darling-Hammond, L. (1999). Reshaping Teaching Policy, Preparation and Practice: influences on the National Board for Teaching Professional Standards. AACTE Publications: Washington, DC.

Darling-Hammond, L. (2010). Evaluating Teacher Effectiveness: How Teacher Performance Assessments Can Measure and Improve Teaching. Center for American Progress: Washington, DC.

Darling-Hammond, L. (2012). The right start: Creating a strong foundation for the teaching career. Kappan, 94(3), 8-13. https://doi.org/10.1177/003172171209400303

Darling-Hammond, L. (2014). One piece of the whole: Teacher evaluation as part of a comprehensive system for teaching and learning. American Educator, 38(1), 4-44.

Ellili-Cherif, M., Romanowski, M. H., \& Nasser, R. (2012). All that glitters is not gold: Challenges of teacher and school leader licensure licensing system in Qatar. International Journal of Educational Development, 32(3), 471-481. https://doi.org/10.1016/j.ijedudev.2011.11.010

Forde, C., McMahon, M. A., Hamilton, G., \& Murray, R. (2016). Rethinking professional standards to promote professional learning. Professional Development in Education, 42(1), 19-35. https://doi.org/10.1080/19415257.2014.999288

Goldhaber, D., \& Anthony, E. (2007). Can teacher quality be effectively assessed? National board certification as a signal of effective teaching. The Review of Economics and Statistics, 89(1), 134-150.

Gyurko, J. (2012). Teacher Voice (Unpublished doctoral dissertation). Columbia University, USA. Retrieved from: https://academiccommons.columbia.edu/catalog/ac\%3A146447

Ingersoll, R. (2011). Power, Accountability, and the Teacher Quality Problem. In S. Kelly (Ed.), Assessing Teacher Quality: Understanding Teacher Effects on Instruction and Achievement (pp. 97-109). Teachers College Press: New York, NY.

Ingvarson, L. (1998). Professional development as the pursuit of professional standards: The standards-based professional development system. Teaching and Teacher Education, 14(1), 127-140. https://doi.org/10.1016/S0742-051X(97)00065-6

Ingvarson, L., \& Rowe, K. (2008). Conceptualising and evaluating teacher quality: Substantive and methodological issues. Australian Journal of Education, 52(1), 5-35. https://doi.org/10.1177/000494410805200102

Isore, M. (2009). Teacher Evaluation: Current Practices in OECD Countries and a Literature Review, OECD Education Working Papers, No. 23, OECD Publishing.

Louden, W., \& Wildy, H. (1999). Short shrift to long lists: An alternative approach to the development of performance standards for school principals. Journal of Educational Administration, 37(2), 99-121. https://doi.org/10.1108/09578239910262944

Mayer, D., Mitchell, J., Macdonald, D., \& Bell, R. (2005). Professional standards for teachers: A case study of professional learning. Asia-Pacific Journal of Teacher Education, 33(2), 159-179. https://doi.org/10.1080/13598660500121977

McMillan, J. H. (2016). National board certified teachers' perspectives on using measures of student learning for teacher evaluation. The Educational Forum, 80(1), 48-60. https://doi.org/10.1080/00131725.2015.1102366

Miles, M. B., \& Huberman, A. M. (1994). Qualitative data analysis: An expanded Sourcebook. Thousand Oaks, CA: Sage.

Mulcahy, D. (2011). Assembling the 'accomplished' teacher: The performativity and politics of professional teaching standards. Educational Philosophy and Theory, 43(1), 94-113. https://doi.org/10.1111/j.1469-5812.2009.00617.x

OECD. (2013). Teachers for the 21st Century: Using Evaluation to Improve Teaching, OECD Publishing. 
Pogodzinski, B., Umpstead, R., \& Witt, J. (2015). Teacher evaluation reform implementation and labor relations. Journal of Education Policy, 30(4), 540-561. https://doi.org/10.1080/02680939.2014.999827

Polikoff, M. S., \& Porter, A. C. (2014). Instructional alignment as a measure of teaching quality. Educational Evaluation and Policy Analysis, 36(4), 399-416. https://doi.org/10.3102/0162373714531851

Romanowski, M. H. (2014a). A Habermasian analysis of Qatar's national teacher professional standards. International Journal of Education, 6(1), 108. https://doi.org/10.5296/ije.v6i1.4816

Romanowski, M. H. (2014b). The Qatar national professional standards for school leaders: A critical discourse analysis using Habermas' theory of knowledge constitutive interests. International Journal of Leadership in Education, 17(2), 174-199. https://doi.org/10.1080/13603124.2013.814808

Romanowski, M. H., \& Amatullah, T. (2014). The impact of Qatar national professional standards: Teachers' perspectives. International Journal of Research Studies in Education, 3(2), 97-114. https://doi.org/10.5861/ijrse.2014.664

Sachs, J. (2003). Teacher professional standards: controlling or developing teaching?. Teachers and Teaching: Theory and Practice, 9(2), 175-186. https://doi.org/10.1080/13540600309373

Sahlberg, P. (2011). The fourth way of Finland. Journal of Educational Change, 12(2), 173-185. https://doi.org/10.1007/s10833-011-9157-y

Sharkey, N. S., \& Goldhaber, D. (2008). Teacher licensure status and student achievement: Lessons from private schools. Economics of Education Review, 27(5), 504-516. https://doi.org/10.1016/j.econedurev.2007.09.009

Supreme Education Council. (2007). National Professional Standards: Creating a Benchmark for Excellence in Teaching. Retrieved from: http://www.sec.gov.qa/En/Media/News/Pages/NewsDetails.aspx?NewsID=2436

Tuinamuana, K. (2011). Teacher professional standards, accountability, and ideology: Alternative discourses. Australian Journal of Teacher Education, 36(12), 72. https://doi.org/10.14221/ajte.2011v36n12.8

Tuytens, M., \& Devos, G. (2014). How to activate teachers through teacher evaluation? School Effectiveness and School Improvement, 25(4), 509-530. https://doi.org/10.1080/09243453.2013.842601

Webb, P. T. (2006). The choreography of accountability. Journal of Education Policy, 21(2), 201-214. https://doi.org/10.1080/02680930500500450

Zellman, G. L., Karam, R., Constant, L., Salem, H., Gonzalez, G., Orr, N., ... \& Al-Obaidli, K. (2009). Implementation of the K-12 Education Reform in Qatar's Schools. Monograph. RAND Corporation: Santa Monica, CA. Retrieved from: http://www.rand.org/pubs/monographs/MG880.html

\section{Copyrights}

Copyright for this article is retained by the author(s), with first publication rights granted to the journal.

This is an open-access article distributed under the terms and conditions of the Creative Commons Attribution license which permits unrestricted use, distribution, and reproduction in any medium, provided the original work is properly cited. 